\title{
ANALYSIS OF THE EFFICIENCY OF WASTEWATER REMEDIATION TECHNOLOGIES USING MICROALGAE
}

\section{Inna Nezbrytska ${ }^{1}$, Sergii Shamanskyi², Sergii Boichenko ${ }^{3}$, Galyna Kharchenko ${ }^{4}$, Lesia Pavliukh ${ }^{5}$}

${ }^{1}$ Department of Water Plants Ecology and Toxicology, Institute of Hydrobiology of National Academy of Sciences of Ukraine, Kyiv, Ukraine

innaimn@ukr.net

ORCID: http://orcid.org/0000-0003-4607-0058

${ }^{2}$ Research Department, National Aviation University, Kyiv, Ukraine

shamanskiy_s i@ukr.net

ORCID: http://orcid.org/0000-0002-6215-3438

${ }^{3}$ National Aviation University, Kyiv, Ukraine,

chemmotology@ukr.net

ORCID: http://orcid.org/0000-0002-1196-3852

${ }^{4}$ Department of Water Plants Ecology and Toxicology, Institute of Hydrobiology of National Academy of Sciences of Ukraine, Kyiv, Ukraine

Shustryk@i.ua

ORCID: http://orcid.org/0000-0002-6102-2129

${ }^{5}$ Department of Ecology, National Aviation University, Kyiv, Ukraine

lenyo@ukr.net

ORCID: http://orcid.org/0000-0002-7715-4601

ARTICLE INFO

Article history:

Received date 23.09.2020

Accepted date 20.10.2020

Published date 30.10.2020

Section:

Waste Management and Disposal

DOI

$10.21303 / 2313-8416.2020 .001459$

KEYWORDS

toxic elements

biogenic elements

heavy metals

remediation

microalgae

biomass

wastewater treatment

water pollution

purification efficiency

\section{ABSTRACT}

The object of research: the technology of wastewater remediation.

Investigated problem: improving the efficiency of biogenic and toxic elements removal from different types of wastewater and reducing the amount of waste in the removal process.

The main scientific results: Possible strains of microalgae, which have ability to absorb biogenic and toxic elements during their metabolism, are identified. It is shown that the use of microalgae is a promising method of wastewater remediation due to their wide availability, the ability to reduce pollution to the established maximum allowable discharge into reservoirs and the ability to accumulate high biomass, which can serve as raw material for industrial products. In particular, Oscillatoria spp. effectively removes chromium, Chlorella vulgaris effectively removes cadmium, copper and zinc, Chlamydomonas spp. effectively removes lead, Euglena gracilis effectively removes nitrogen and phosphorus compounds.

It is also shown that the most effective way to solve the problem of restoring the biomass of algae obtained in wastewater is to use immobilized cell systems. The use of immobilized systems can also increase the resistance of cells and the rate of their removal of various pollutants and xenobiotics from wastewater.

The area of practical use of the research results: Municipal enterprises for domestic and surface wastewater treatment. Enterprises for the treatment of industrial effluents. Enterprises for biomass processing, production of motor fuels, biogas, organic fertilizers.

Innovative technological product: The technology of remediation of domestic, surface and industrial wastewater, which allows to effectively purify these waters from toxic and biogenic elements and reduce pollution of surface water bodies. The technology assumes the absence of waste, as the resulting biomass of microalgae is considered as a raw material for the production of various products. Scope of the innovative technological product: Technological schemes of domestic, rain and industrial wastewater remediation, protection water bodies from pollution, improvement of surface water quality.

(C) The Author(s) 2020. This is an open access article under the CC BY license http://creativecommons.org/licenses/by/4.0).

\section{Introduction}

\section{1. The object of research}

The object of research is the technology of remediation of wastewater with the help of microalgae using the process of their metabolism.

\section{2. Problem description}

Protecting the environment from pollution with sewage water is one of today's pressing issues. The development of cities, industry and agriculture inevitably leads to increase in wastewater 
discharge and increased pollution of natural water with various organic (petroleum products, pesticides, synthetic surfactants, etc.) and inorganic (heavy metals, nitrates, phosphates, etc.) substances. Reducing environmental damage can be achieved by finding optimal ways to treat wastewater and reuse it. The most effective ways to remove pollutants from aquatic environments are chemical, physical and biological methods. However, the use of chemical reagents causes secondary water pollution, and the use of physical methods is limited by their high cost.

Biotechnological methods of wastewater remediation have become of an increasing interest. It is because they are characterized by high efficiency, low cost, ease of implementation and are environmentally friendly. One of the promising ways of realizing them is the use of microalgae (phytoremediation) [1,2].

\section{3. Suggested solution to the problem}

Microalgae have recently become attractive biological systems for wastewater remediation due to their important role in the absorption of pollutants from the aquatic environment and the ability to produce valuable biomass that can be used in various industries [1]. The first purpose of using microalgae for wastewater remediation was to remove residual amounts of biogenic elements [3]. In the process of bioremediation of microalgae, nitrogen and phosphorus compounds are accumulated for the synthesis of organic substances necessary for growth: pigments, amino acids, proteins, enzymes, nucleic acids, phospholipids, etc. Microalgae are characterized by tolerance to a wide range of concentrations of biogenic elements in water. In addition, under conditions of excess phosphorus, they can accumulate it in special polyphosphate and metaphosphate granules.

During photosynthesis, microalgae use light as a source of energy and $\mathrm{CO}_{2}$ as a source of carbon. Thus, this process helps to reduce the concentration of $\mathrm{CO}_{2}$. In fact, these photosynthetic organisms reduce the need for mechanical aeration during wastewater remediation. Due to the high lability of metabolism, they can function in the absence of light as heterotrophic organisms and use organic carbon to maintain their vital functions. Algae intensively utilize from wastewater not only nitrogen- and phosphorus-containing compounds, but also heavy metals, which are often found in industrial wastewaters and in wastewaters of transport industries [4].

Accumulation of heavy metals by algae cells includes two stages: passive (fast) absorption and active (much slower) absorption. During passive absorption, physical adsorption occurs, in which metal ions are rapidly adsorbed by the cell surface and this process does not depend on metabolism.

Then there is chemisorption occurs - a process in which ions are slowly transported across the cell membrane into the cytoplasm, it depends on the peculiarities of metabolism. Different types of algae are characterized by different removal efficiency of heavy metals. For example, chromium effectively removes Oscillatoria spp., Cadmium, copper and zinc-Chlorella vulga ris, lead-Chlamydomonas spp. [4].

Microalgae effectively absorb surfactants and phenolic compounds out of wastewater. Such species as Scenedesmus sp., Chlamydomonas sp., Botryococcus braunii and Chlorella sp. are characterized by high specific growth rate $(0.354-0.501$ days -1$)$ and high lipid content $(22-42 \%$ in terms of dry matter) when cultivated in wastewater with similar pollutants [5].

Cultivation of microalgae in wastewater, on the one hand, allows carrying out biological water remediation, on the other hand, it allows obtaining cheap biomass rich in lipids. The use of wastewater is considered a promising alternative to synthetic media [2]. The use of such an environment can significantly reduce the cost of cultivation due to the high availability and presence in their composition of biogenic elements, which are necessary for the growth of algae, some vitamins and metals. Wastewater $\mathrm{pH}$ and $\mathrm{CO}_{2}$ saturation are generally sufficient for efficient cultivation of microalgae, and additional treatment of microflora increases biomass yield.

It is possible to simultaneously provide an efficient method of wastewater remediation and a cheap method of obtaining biomass for biofuel production by using sewage for algae cultivation. Therefore, the use of algae in wastewater remediation technologies has a number of advantages, in particular: improved oxygen regime due to photosynthetic aeration, reducing the concentration of pollutants by absorption and/or transformation, synthesis of biologically active metabolites that can be used for industrial purposes. 
The aim of the research is identifying strains of microalgae, which are capable of efficient absorption of toxic and biogenic elements from different types of wastewater during metabolism, as well as finding the most effective method of removing microalgae biomass from wastewater after completion of the remediation process.

\section{Materials and Methods}

Traditionally, microalgae are used for wastewater remediation in algae-bacterial ponds or high-tech intensive algae ponds [4].

Ponds in which wastewater stabilization occurs under aerobic or optional conditions are called "waste stabilization ponds". The most common type of ponds that use algae is facultative ponds to stabilize waste. These ponds allow providing efficient wastewater remediation and algal biomass accumulation. The processes of wastewater remediation (oxidation, precipitation, adsorption, disinfection) are the result of symbiotic relationships between populations of algae and bacteria. Algae support the aerobic bacterial oxidation of organic matter (due to the release of oxygen during photosynthesis), however, carbon dioxide and nutrients formed during aerobic oxidation are used by microalgae (Fig. 1).

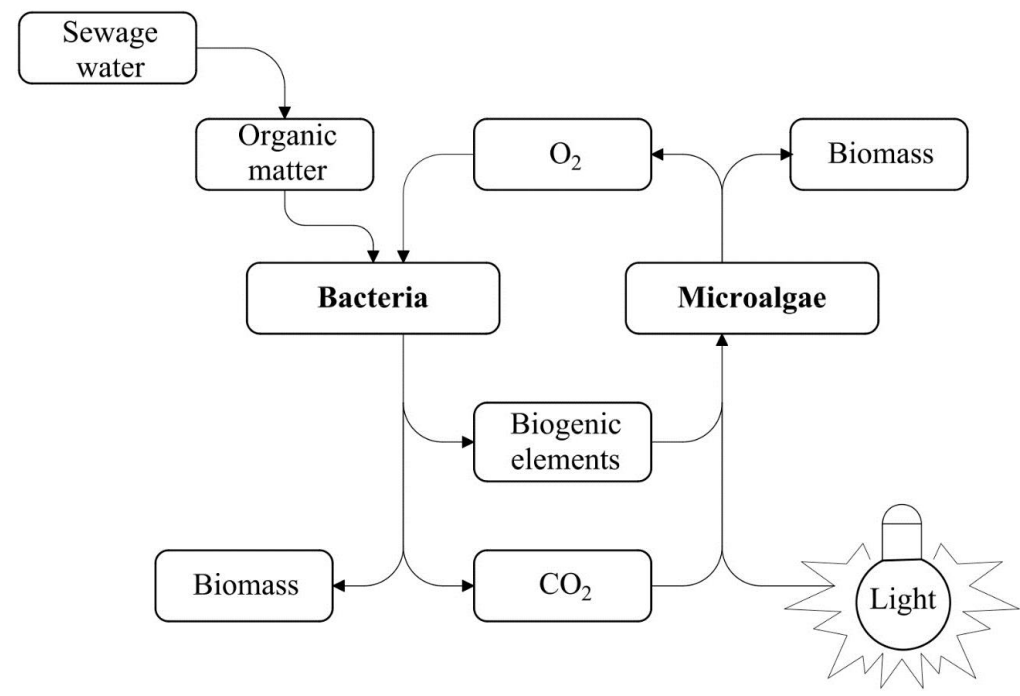

Fig. 1. Removal of biogenic elements out of wastewater and biomass production in algal-bacterial systems [2]

Facultative reservoirs (usually $2.5 \mathrm{~m}$ deep) are systems where the quality of effluents improves within 5-30 days, depending on a number of factors: temperature, light intensity, aeration rate and surface area. There are three main zones in these ponds: the upper two - provided with oxygen and the lower zone with anaerobic conditions (Fig. 2). Photosynthesis of algae and atmospheric air are the main sources of oxygen in the upper layers. Stabilization of wastewater with the participation of algae-bacterial cultures occurs in the aerobic zone of ponds. Degradation of pollutants with the participation of anaerobic bacteria occurs in the lower zone.

High-tech intensive algae ponds (HRAP) are small open ponds (depth 15-25 cm), provided with mechanical aeration and mixing with an impeller (Fig. 3). High levels of oxygen, as a result of photosynthesis, and aeration can reduce the retention time of sewage water. Reduction of biochemical oxygen demand is $90 \%$, nitrogen and phosphorus more than $80 \%$ in intensive algae ponds during a few days. These ponds are used for the remediation of various types of wastewater and cultivation of industrially valuable species of algae: Chlorella spp., Arthrospira spp., Hematococcus spp. [1].

Despite the relative ease of operation, the cultivation of microalgae in open systems is accompanied by contamination and depends on weather conditions (low efficiency in the cold season and high water loss due to evaporation), so closed cultivation systems are often used. The latter include photobioreactors, which allow to maintain stable cultivation conditions, including $\mathrm{CO}_{2}$ concentration, mixing rate, temperature and biogenic elements uptake. In addition, photobioreactors 
provide large surface area and, consequently, better illumination. Water evaporation is minimized through the use of a closed system [4]. However, the use of a particular system for cultivation should be determined by both the physiological properties of the microalgae culture and the requirements for the scale of this process.

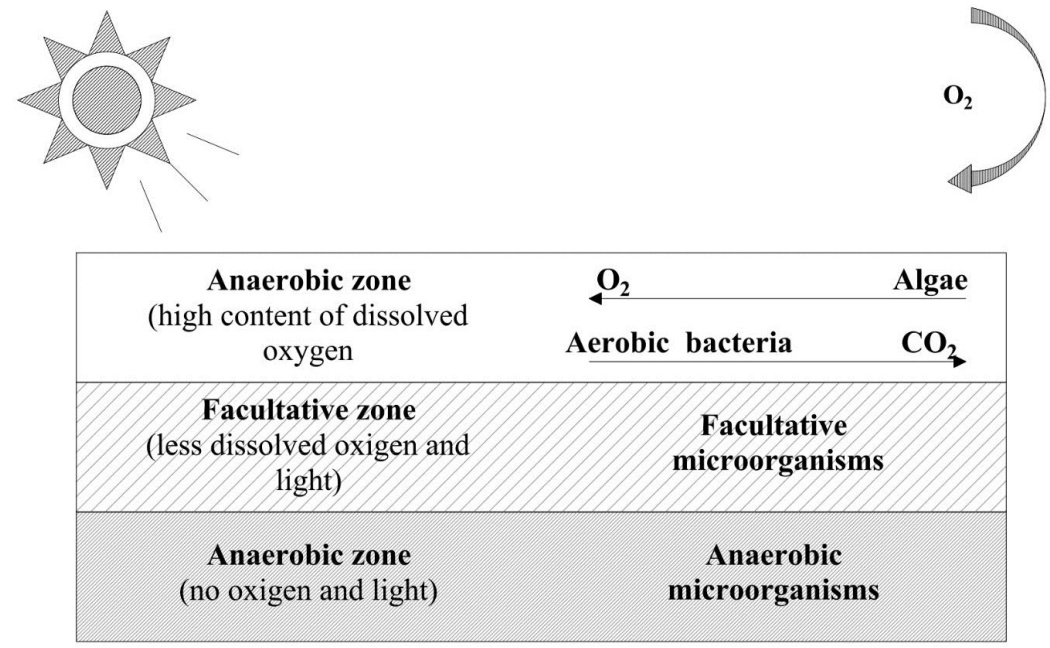

Fig. 2. Sewage water remediation scheme in a facultative pond

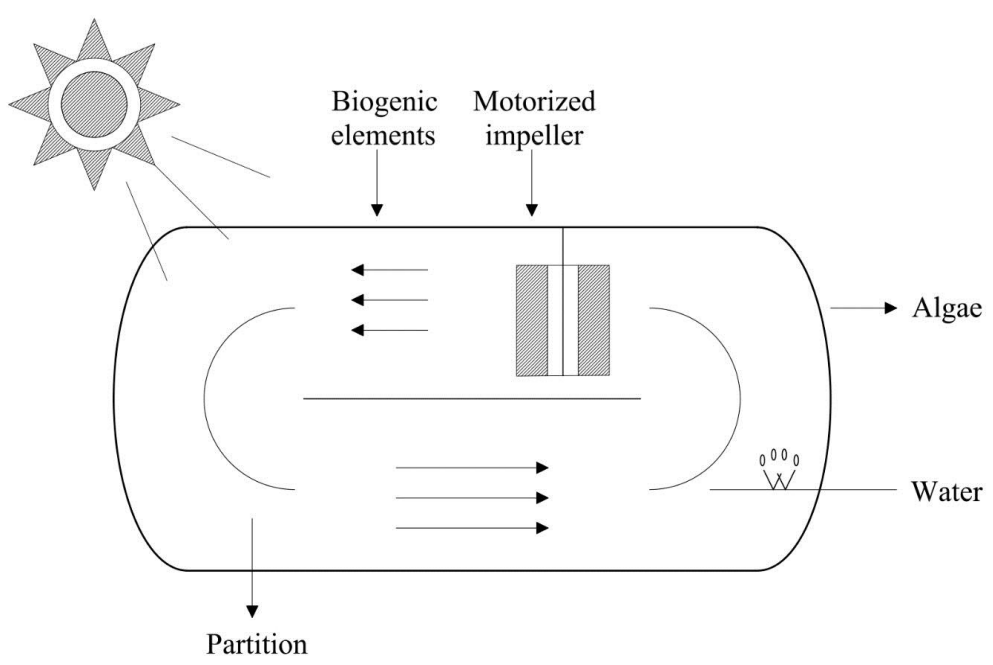

Fig. 3. Scheme of wastewater remediation with algae in a high-tech intensive algae pond

\section{Results}

Wastewater remediation using microalgae is considered effective when their biomass is removed and recovered. Restoration of microalgae biomass is one of the main problems when using microalgae for phytoremediation. The solution to this problem can be achieved by using a system of immobilized cells. The main feature of the technology of immobilization is that the cells of microalgae are placed in a certain retaining substance. The physicochemical principles underlying it allow cells to be fixed in such a way that their activity is maintained for a long time, while they do not undergo structural changes [6].

There are two groups of immobilization methods today: passive and active. Passive immobilization is based on the natural ability of microorganisms to attach to substrates. This is the simplest way to immobilize algae cells, which does not cause stress and mimics the natural process of attaching cells to substrates. For passive immobilization use the fruits of loofah, plastic, wood [7]. Loofah fruits are quite good carriers because they are porous, non-toxic and cheap.

Active methods of immobilization do not depend on the natural ability of cells of microorganisms to attach to any substrate and include two main approaches: 
- binding to the surface of the carrier using "crosslinking" agents;

- inclusion in the spatial structure of the carrier.

Both synthetic and natural materials, in particular chitin or chitosan, can be used to bind the cells to the surface of the carrier.

Immobilization with the inclusion of cells in the spatial structure of the carrier involves the use of various polymers, such as agarose or agaropectin. The advantages of agar include environmental safety, low melting point and the ability to form dense gels. Alginates and carrageenan are also promising carriers. The growth of algae cells in these granules is not limited by light intensity and they are non-toxic.

\section{Discussion}

Immobilized cells become more resistant to changes in $\mathrm{pH}$, temperature and ionic strength of the environment. There is also an increase in the resistance of cells to various toxic substances [7].

Despite the limited growth of the culture in the granules, the metabolic activity of immobilized cells, compared with suspended cells, may be higher, which helps to increase the rate of wastewater remediation. Immobilized cell systems are particularly effective in removing biogenic elements and various metals out of wastewater.

Thus, the advantages of using systems of immobilized cells of microalgae are:

- increasing the resistance of microalgae cells to adverse environmental factors;

- easy separation of immobilized microalgae cells from the liquid phase;

- possibility of repeated cultivation;

- increasing the efficiency of wastewater treatment out of different pollutants.

Membrane bioreactors, which demonstrate more and more prospects for application, can be new equipment for wastewater remediation. Membrane bioreactors are hybrid equipment that consists, depending on the field of application, of two main elements: bioreactors and membrane modules or units combined with them into a single system. In principle, the membrane bioreactor operates as following. The bioreactor receives wastewater that has previously undergone mechanical treatment. The process of separation of purified water and microalgae is carried out using micro- and ultrafiltration membranes, through which the mixture is filtered. Water purification is given for final disposal, and microalgae are returned for reuse [8].

Bioreactors can also be designed for the biosynthesis of macromolecular biologicals, food products and biologically active food additives or vice versa for the hydrolysis (enzymolysis, autolysis) of macromolecular substances to low molecular weight ingredients, such as amino acids or polypeptides $[9,10]$.

The structure of membrane bioreactors can be of two main types: with submerged (built-in) and remote pressure diaphragm modules. The most widespread in the industry were pressureless bioreactors with submerged membrane modules, mainly for wastewater treatment [11, 12]. In food biotechnology, bioreactors with remote membrane installations have become the most widespread during the production of lactic, propionic acid, acetic and citric acids.

It should be noted that the use of microalgae for remediation has its limitations. The effect of toxic elements on metabolism can't be called well studied. This study shows that at relatively low concentrations of heavy metals in wastewater microalgae effectively absorb them and give a fairly good increase in biomass. At high concentrations, inhibition of metabolism is observed. Determining the concentration limits of various heavy metals and other inhibitors using different strains of microalgae may be the direction of further research in this area.

\section{Conclusions}

Implementation of microalgae metabolism is an effective method of wastewater remediation. It is because they have high ability to absorb different types of pollution from wastewater and can provide achieving established maximum allowable concentration of the pollutants. It improves quality of discharged wastewaters into water bodies. On the other hand, accumulated biomass of microalgae can be considered as raw material for production different types of valuable products.

The study identified the strains of microalgae that are most promising for using in remediation, namely those that have the greatest absorptive capacity for biogenic elements and toxic compounds, as well as the ability to rapidly increase their biomass while growing. It also shows 
that these strains they can be used for reducing the concentrations of pollutants in wastewater to the established maximum allowable levels before discharging into water bodies. Different strains of microalgae can be used to remediate different types of wastewater with different contaminants and their concentrations.

The most effective method to restore the biomass of microalgae from the wastewater after completion of the remediation process is implementing immobilized cell systems. In addition the implementation of these systems increases the resistance of cells and also increases the rate of remediation, in particular the rate of various pollutants and xenobiotics removal out of wastewater.

\section{References}

[1] Abdel-Raouf, N., Al-Homaidan, A. A., Ibraheem, I. B. M. (2012). Microalgae and wastewater treatment. Saudi Journal of Biological Sciences, 19 (3), 257-275. doi: http://doi.org/10.1016/j.sjbs.2012.04.005

[2] Eladel, H., Esakkimuthu, S., Abomohra, A.; Gupta, S. K., Bux, F. (Eds.) (2019). Dual role of microalgae in wastewater treatment and biodiesel production. Application of microalgae in wastewater treatment. Cham: Springer, 85-121. doi: http://doi.org/ 10.1007/978-3-030-13909-4_5

[3] Madkour, A. G., Rasheedy, S. H., Dar, M. A. et. al. (2017). The differential efficiency of Chlorella vulgaris and Oscillatoria sp. to treat the municipal wastewater. Journal of Biology, Agriculture and Healthcare, 7 (22), 83-94.

[4] Molazadeh, M., Ahmadzadeh, H., Pourianfar, H. R., Lyon, S., \& Rampelotto, P. H. (2019). The Use of Microalgae for Coupling Wastewater Treatment With CO2 Biofixation. Frontiers in Bioengineering and Biotechnology, 7. doi: http://doi.org/10.3389/ fbioe. 2019.00042

[5] Hena, S., Abida, N., Tabassum, S. (2015). Screening of facultative strains of high lipid producing microalgae for treating surfactant mediated municipal wastewater. RSC Advances, 5 (120), 98805-98813. doi: http://doi.org/10.1039/c5ra20019a

[6] Pandian, S. K., Thomas, J. (2019). Integrated study on nutrients and heavy metals removal from domestic wastewater using free and immobilized strain Scenedesmus rubescens KACC 2 (Chlorophyta, Chlorophyceae). Algologia, 29 (1), 88-103. doi: http://doi.org/10.15407/alg29.01.088

[7] Vasilieva, S. G., Lobakova, E. S., Lukyanov, A. A., Solovchenko, A. E. (2016). Immobilized microalgae in biotechnology. Moscow University Biological Sciences Bulletin, 71 (3), 170-176. doi: http://doi.org/10.3103/s0096392516030135

[8] Boichenko, S. V., Boichenko, M. S., Shamanskyi, S. I. (2020). Application of membrane bioreactors for wastewater treatment from bioresistant pharmaceutical products. Science-Based Technologies, 1 (45), 67-77. doi: http://doi.org/10.18372/23105461.45.14573

[9] Bonnanfant, M., Jesus, B., Pruvost, J., Mouget, J.-L., Campbell, D. A. (2019). Photosynthetic electron transport transients in Chlorella vulgaris under fluctuating light. Algal Research, 44, 101713. doi: http://doi.org/10.1016/j.algal.2019.101713

[10] Nghiem Xuan, R., Safitri, I., Mouget, J. L., Pruvost, J., Turpin, V., Jaouen, P. (2020). Design of an artificial culture medium to optimize Haslea ostrearia biomass and marennine production. Algal Research, 45, 101653. doi: http://doi.org/10.1016/ j.algal.2019.101653

[11] Yang, J., Rasa, E., Tantayotai, P., Scow, K. M., Yuan, H., Hristova, K. R. (2011). Mathematical model of Chlorella minutissima UTEX2341 growth and lipid production under photoheterotrophic fermentation conditions. Bioresource Technology, 102 (3), 3077-3082. doi: http://doi.org/10.1016/j.biortech.2010.10.049

[12] Mansouri, M. (2016). Predictive modeling of biomass production by Chlorella vulgaris in a draft-tube airlift photobioreactor. Advances in Environmental Technology, 3, 119-126. doi: http://doi.org/10.22104/AET.2017.433 